\title{
Special Issue: Recent Advances in Plant Leaf Classification
}

\author{
Abdul Kadir ${ }^{a}$ and George A. Papakostas ${ }^{b}$ \\ ${ }^{a}$ Faculty of Engineering Technology, Universiti Teknikal Malaysia Melaka (UTeM), Malaysia \\ ${ }^{b}$ Department of Computer and Informatics Engineering, Eastern Macedonia and Thrace (EMT) \\ Institute of Technology, St. Lukas, GR-65404 Kavala, Greece \\ e-mail: abdulkadir@utem.edu.my,gpapak@teikav.edu.gr
}

\section{Editorial}

The classification of the plants through leaf processing has attracted the scientific interest in the last decade. To this end, several recognition systems for the identification of plant species, based on the visual information of their leaves, have been proposed with great success. Such systems find application in helping the scientists in the fields of botanology, agriculture etc. to characterize and analyze the plants. Moreover, they serve as a utility to the everyday person (naturalist) who wishes to learn and identify the different species of the nature, during his/her activities. Considering the aforementioned needs, computer scientists have proposed new feature extraction methods, classification schemes, image processing algorithms, etc. in order to construct stable and efficient classification systems.

In this evolving research topic, where many new methodologies are being proposed day by day, this special issue consisting of three distinctive papers, aims to capture the recent trends in plant leaf classification.

The first paper written by Abdul Kadir proposes a novel approach that combines Fourier descriptors with other shape features in order to identify the plant leaves.

The second paper written by T. Vijayashree and A.Gopal proposes a new database consisting of 50 samples of tulsi leaves under various conditions. This database can help scientists to classify and authenticate tulsi leaves for herbal medicines.

The third paper written by Manisha Amlekar et al. presents a comparison of the Sobel and Canny edge detection methods as part of a plant leaf classification system.

We would like to thank all the authors who submitted their papers. We are especially grateful to the Publishing Manager of Science Gate Publishing, Maria Katefidou for her dedication to the publication of this special issue. 